\title{
Phase II study of neoadjuvant therapy with nab-paclitaxel and cisplatin followed by surgery in patients with locally advanced esophageal squamous cell carcinoma
}

\author{
Yun Fan ${ }^{1,2}$, Youhua Jiang ${ }^{3}$, Xinming Zhou ${ }^{3}$, Qixun Chen ${ }^{3}$, Zhiyu Huang ${ }^{1}$, Yanjun \\ $\mathrm{Xu}^{1}$, Lei Gong ${ }^{1}$, Haifeng $\mathrm{Yu}^{1}$, Haiyan Yang ${ }^{1}$, Jinshi Liü ${ }^{3}$, Tao Lei $^{1}$, Qiang Zhao ${ }^{3}$ and \\ Weimin Mao $^{1,2}$ \\ ${ }^{1}$ Department of Chemotherapy, Zhejiang Cancer Hospital, Hangzhou, China \\ ${ }^{2}$ Key Laboratory Diagnosis and Treatment Technology on Thoracic Oncology and Cancer Research Institute, Hangzhou, China \\ ${ }^{3}$ Department of Thoracic Surgery, Zhejiang Cancer Hospital, Hangzhou, China \\ Correspondence to: Weimin Mao, email: 21972483@qq.com \\ Keywords: esophageal squamous cell carcinoma; nab-paclitaxel; cisplatin; neoadjuvant chemotherapy; esophagectomy \\ Received: February 13,2016 Accepted: April 26, 2016 \\ Published: May 23, 2016
}

\section{ABSTRACT}

Background: We carried out a phase II study to evaluate the efficiency and safety of the combination of nanoparticle albumin bound-paclitaxel (nab-paclitaxel) and cisplatin as preoperative chemotherapy for locally advanced esophageal squamous cell carcinoma (ESCC).

Results: From Oct 2011 to Dec 2012, 35 patients were enrolled and received neoadjuvant chemotherapy. Thirty patients underwent surgery and achieved a $100 \%$ RO resection. Pathological complete response (PCR) rate was $13.3 \%$ and near PCR rate was $6.7 \%$. Down-staging was achieved in 19 patients. With median follow-up of 37.8 months, 16 patients were still alive. One-, 2- and 3- year overall survival

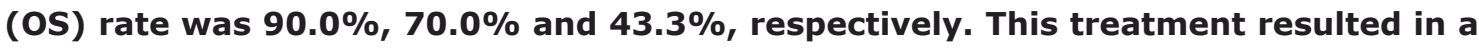
median disease-free survival (DFS) of $\mathbf{3 4 . 7}$ months and a median OS of $\mathbf{3 7 . 8}$ months. Median DFS and OS of down-staged patients were significantly longer than those of non-downstaged patients. The grade 4 toxicities during neoadjuvant chemotherapy were limited to neutropenia $(2.9 \%)$ and vomiting $(2.9 \%)$.

Methods: Patients with locally advanced ESCC (stage IIA to IIIC) and performance status 0-1 were enrolled and received two cycles of nab-paclitaxel $\left(100 \mathrm{mg} / \mathrm{m}^{2}\right)$ on day 1, 8, 22 and 29, and cisplatin $\left(75 \mathrm{mg} / \mathrm{m}^{2}\right)$ on day 1 and 22, followed by resection. Two cycles of adjuvant chemotherapy with the same regimen were given. Postoperative radiotherapy was permitted and decided by radiation therapist.

Conclusion: Weekly nab-paclitaxel with three-weekly cisplatin seems effective and safe as a neoadjuvant chemotherapy strategy for locally advanced ESCC. Downstaged patients have favorable outcome.

ClinicalTrials.gov Identifier: NCT01258192

\section{INTRODUCTION}

Esophageal cancer is a malignant tumor with a poor prognosis that is common in China [1]. According to the 2014 Chinese cancer registry annual report, the incidence of esophageal carcinoma was 22.87 per 10 million, ranking fifth; the annual mortality rate was 17.35 per 10 million, ranking forth [2]. With surgery alone, the 5-year survival rate for T2-T3N0 disease is $<30-40 \%$, and it declines to $<25 \%$ with nodal involvement [3]. Despite substantial advances in the multidisciplinary therapy for locally advanced resectable esophageal cancer, prognosis remains poor.

Many clinical studies had explored the efficacy and safety of neoadjuvant therapy for locally advanced esophageal carcinoma. Some of them reported positive 
Table 1: The clinical characteristics of patients enrolled $(N=35)$.

\begin{tabular}{|l|l|}
\hline Characteristics & Patients, $N(\mathbf{\%})$ \\
\hline Sex & \\
\hline \multicolumn{1}{|c|}{ male } & $31(88.6)$ \\
\hline Age, years & $4(11.4)$ \\
\hline median & \\
\hline Range & 59 \\
\hline Tumor location & $48-70$ \\
\hline Middle third & \\
\hline Distal third & $30(85.7)$ \\
\hline ECOG performance status & $5(14.3)$ \\
\hline 0 & $25(71.4)$ \\
\hline 1 & $10(28.6)$ \\
\hline Clinical T stage & \\
\hline T1 & $0(0)$ \\
\hline T2 & $9(25.7)$ \\
\hline T3 & $20(57.1)$ \\
\hline T4 & $6(17.1)$ \\
\hline Clinical N stage & \\
\hline N0 & $7(20)$ \\
\hline N1 & $10(28.6)$ \\
\hline N2 & $13(37.1)$ \\
\hline N3 & $5(17.3)$ \\
\hline Clinical stage & \\
\hline IIA & $3(8.6)$ \\
\hline IIB & $5(14.3)$ \\
\hline IIIA & $10(28.6)$ \\
\hline IIIB & $8(22.9)$ \\
\hline IIIC & $9(25.7)$ \\
\hline
\end{tabular}

ECOG, Eastern Cooperative Oncology Group.

results, which suggest that neoadjuvant therapy, chemotherapy alone or combined with radiotherapy, can benefit patients and improve prognosis [4-8]. Although part of researchers prefer preoperative chemoradiation in esophageal cancer, neoadjuvant chemotherapy seems much safer with a reduced postoperative mortality [910]. Moreover, although preoperative chemoradiation is a standard strategy in the treatment of locally advanced esophageal cancer in USA, an updated meta-analysis shows no clear advantage of neoadjuvant chemoradiation over neoadjuvant chemotherapy alone [11]. Of note, when limited to the patients with ESCC included in that meta-analysis ( $65 \%$ of patients with SCC), neoadjuvant chemoradiation significantly increased survival versus surgery alone but not versus neoadjuvant chemotherapy [11]. Thus, the value of preoperative chemotherapy still needs further substantiation.

Even if trials often had been designed to evaluate the survival benefits from cisplatin and 5-fluorouracil (FU) as a preoperative chemotherapy scheme $[10,12-13]$ the best neoadjuvant chemotherapy regimen has not been well established. Nab-Paclitaxel (nab-PC) is a new generation formulation of paclitaxel. It is a solvent-free albuminbound form of paclitaxel [14-16]. When compared with solvent-based-paclitaxel (sb-PC), nab-PC has various advantages, including the ability to deliver higher doses of paclitaxel over a shorter infusion time (30 minutes vs 3 hours for sb-PC) and the elimination of pre-medications to prevent hypersensitivity reaction. Other advantages of nab-PC over sb-PC include enhanced transport of paclitaxel across endothelial cells and greater delivery of paclitaxel to tumors. In a preclinical study, more than fourfold nab-PC was transported across endothelial cells than sb-PC [16]. A phase III trial compared the effects of weekly nab-PC versus sb-PC in combination with carboplatin for first-line treatment of non-small cell lung cancer (NSCLC). Weekly nab-PC outclassed sb$\mathrm{PC}$ resulting in a significantly improved overall response rate (ORR) in advanced NSCLC [17]. Moreover, the combination of nab-PC and cisplatin had already been 
Table 2: Histopathologic analysis and tumor down-staging

\begin{tabular}{|l|l|l|l|}
\hline & $\mathbf{N}(N=\mathbf{3 0}, \mathbf{\%})$ & & $\mathbf{N}(N=\mathbf{3 5 \%})$ \\
\hline pCR & $4(13.3)$ & CR & $6(17.1)$ \\
\hline Near pCR & $2(6.7)$ & PR & $17(48.6)$ \\
\hline R0 resection rate & $30(100)$ & PD & $2(5.7)$ \\
\hline Down-staging rate & $19(63.3)$ & ORR & $33(65.7)$ \\
\hline
\end{tabular}

pCR: pathologic complete response

Near pCR: microfoci of tumor cells on the primary tumor without lymph nodal metastasis

$\mathrm{R} 0$ : the resection was defined as curative

$\mathrm{CR}$ : complete response

realized as a highly effective and well-tolerated first-line treatment in metastatic ESCC [18]. Based on the hot issues in locally advanced esophageal cancer therapy, we carried out a phase II clinical study to determine the pathological response rate, efficacy and safety of preoperative neoadjuvant chemotherapy with weekly nab-PC and cisplatin in treating locally advanced ESCC.

\section{RESULTS}

From Oct 2011 to April 2012, 10 patients were enrolled and received 2 cycles of neoadjuvant chemotherapy with nab-PC and cisplatin. They all subsequently underwent surgery. The enrollment was continued when there were 20\% (2/10) pCR. Finally, 35 patients were enrolled until Dec 2012 at Zhejiang Cancer Hospital, including 31 males and 4 females, with a median age of 59 year (48-70 year) (Table 1). All patients had biopsy-proven resectable locally advanced squamous cell carcinoma of the middle third and distal third of esophagus and an Eastern Cooperative Oncology Group (ECOG) Performance Status 0-1 (Figure 1). Stage II A, II $\mathrm{B}$, III A, III B and III C disease was found in $3(8.6 \%), 5$ $(14.3 \%), 10(28.6 \%), 8(22.9 \%)$ and $9(25.7 \%)$ patients, respectively. The clinical characteristics of patients are listed in Table 1. All 35 patients have completed the two cycles of neoadjuvant chemotherapy. Thirty patients $(30 / 35,85.7 \%)$ underwent surgery after 2 cycles of neoadjuvant chemotherapy (Figure 2).

\section{Treatment}

Total planned doses of nab-PC and cisplatin were administered in $100 \%$ of patients. Five patients did not receive surgery after neoadjuvant chemotherapy, among them 2 suffered progressive disease and were unable to undergo radical resection, 3 refused surgery. Twenty-four patients $(24 / 30,80.0 \%)$ accepted two cycles of adjuvant chemotherapy with the same regimen after surgery, and among them, 7 patients $(7 / 30,23.3 \%)$ received adjuvant radiotherapy after adjuvant chemotherapy (Figure 2).

\section{Efficacy of neoadjuvant chemotherapy}

The ORR (according to RECIST version 1.1) after completion of 2 cycles of neoadjuvant chemotherapy with nab-PC and cisplatin amounted to $65.7 \%$ (complete response (CR): 6/35, partial response (PR): 17/35) as evaluated by enhancement thoracoabdominal CT scan.
1. Histologically comfirmed

esophageal cancer

2. Potentially curable

squamous cell carcinoma

3. Middle third and distal third

of esophagus

4. Clinical stage(AJCC 7) II-III

5. ECOG PS 0-1

6. $N=30$
Adjuvant CT:

Additional 2 cycles of the same regimen

Adjuvant RT was at the radiation oncologists' discretion

Figure 1: Study design. All patients had biopsy-proven resectable locally advanced squamous cell carcinoma of the middle third and distal third of esophagus and an ECOG Performance Status 0-1. All eligible patients received nab-PC (100 mg/m2, d1, d8, d22 and d29) and cisplatin $(75 \mathrm{mg} / \mathrm{m} 2, \mathrm{~d} 1$ and $\mathrm{d} 22)$ as neoadjuvant chemotherapy, followed by esophagectomy and adjuvant chemotherapy with or without radiotherapy. 
Table 3: Toxicities in 35 evaluable patients during neoadjuvant chemotherapy.

\begin{tabular}{|l|l|l|l|}
\hline Adverse events & G1-G4 (\%) & $\mathbf{G 3 ,} N(\mathbf{\%})$ & $\mathbf{G 4 ,} N(\mathbf{\%})$ \\
\hline Hematologic & & & \\
\hline Anemia & $21(60)$ & $3(8.6)$ & $0(0)$ \\
\hline Neutropenia & $25(71.4)$ & $3(8.6)$ & $1(2.9)$ \\
\hline Thrombocytopenia & $6(17.1)$ & $2(5.7)$ & $0(0)$ \\
\hline Nonhematologic & & & \\
\hline Febrile neutropenia & $5(14.3)$ & $3(8.6)$ & $0(0)$ \\
\hline Fatigue & $15(42.9)$ & $0(0)$ & $0(0)$ \\
\hline Nausea & $28(80)$ & $2(5.7)$ & $0(0)$ \\
\hline Vomiting & $19(54.3)$ & $4(11.4)$ & $1(2.9)$ \\
\hline Diarrhea & $1(2.9)$ & $0(0)$ & $0(0)$ \\
\hline Alopecia & $10(28.6)$ & $0(0)$ & $0(0)$ \\
\hline Sensory neuropathy & $6(17.1)$ & $0(0)$ & $0(0)$ \\
\hline ALT & $2(5.7)$ & $0(0)$ & $0(0)$ \\
\hline
\end{tabular}

\section{Histopathologic analysis and tumor down-staging}

All of the 30 patients who underwent surgery had R0 resection (100\%). pCR was achieved in 4 patients $(4 / 30$, $13.3 \%$ ) and near pCR (defined as microfoci of tumor cells on the primary tumor without lymph nodal metastasis) in 2 patients $(2 / 30,6.7 \%)$. Significant down-staging was observed in 19 patients $(19 / 30,63.3 \%)$ (Table 2).

\section{Survival}

The entire 30 patients who underwent surgery were followed up. Median follow-up was 37.8 months. Total number of deaths was $14(46.7 \%)$ while $16(50.4 \%)$ patients were still alive. Moreover, 14 patients were alive without disease relapse. One-, 2- and 3-y OS rates were $90.0 \%, 70.0 \%$ and $43.3 \%$, respectively, and $1-, 2-$ and $3-y$ DFS rates were $83.3 \%, 46.7 \%$ and $40.0 \%$, respectively. The treatment resulted in a median DFS of 34.7 months and a median OS of 37.8 months. OS and DFS were not significantly different between patients with stage II and

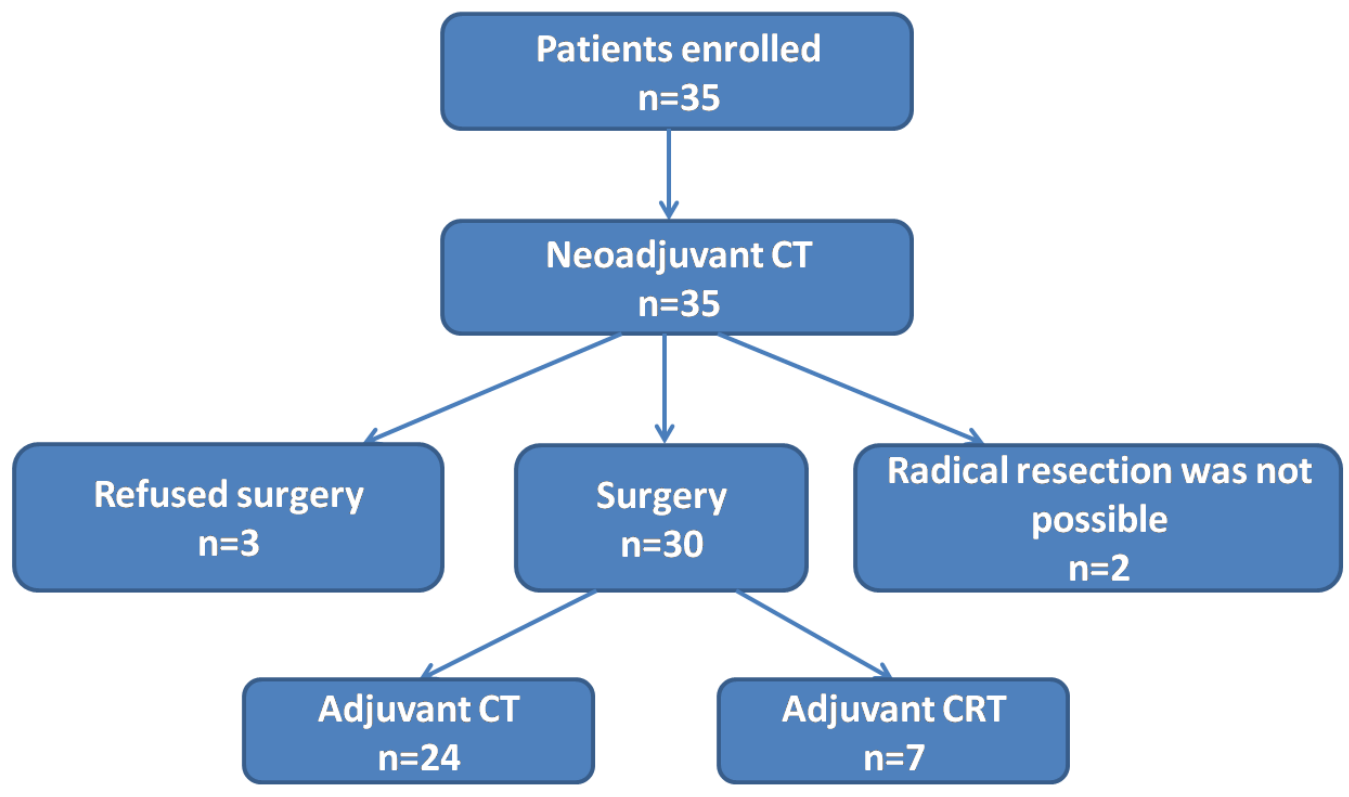

Figure 2: Study scheme. Total planned doses of nab-PC and cisplatin were administered in 35 patients. Five patients did not receive surgery after neoadjuvant chemotherapy, among them 2 suffered progressive disease, 3 refused surgery. Twenty-four patients accepted two cycles of adjuvant chemotherapy (CT) with the same regimen after surgery, and 7 patients received adjuvant radiotherapy after adjuvant chemotherapy (CRT). 
A

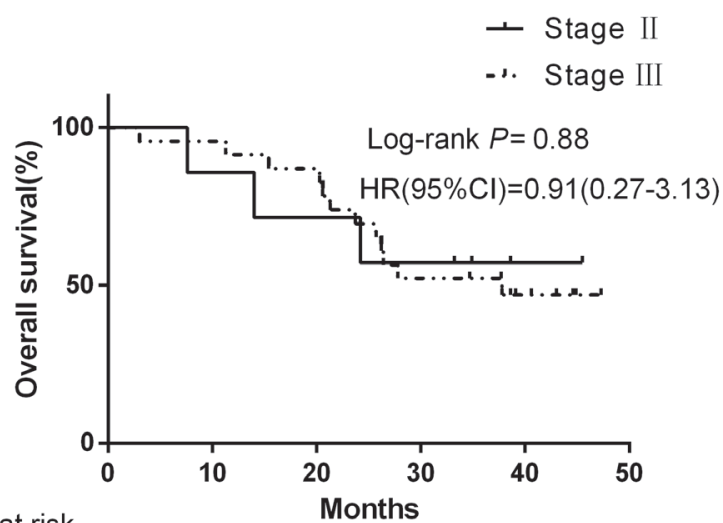

No. at risk

$\begin{array}{lrrrrr}\text { Stage II } & 7 & 7 & 6 & 5 & 2 \\ \text { Stage III } & 23 & 23 & 21 & 13 & 6\end{array}$
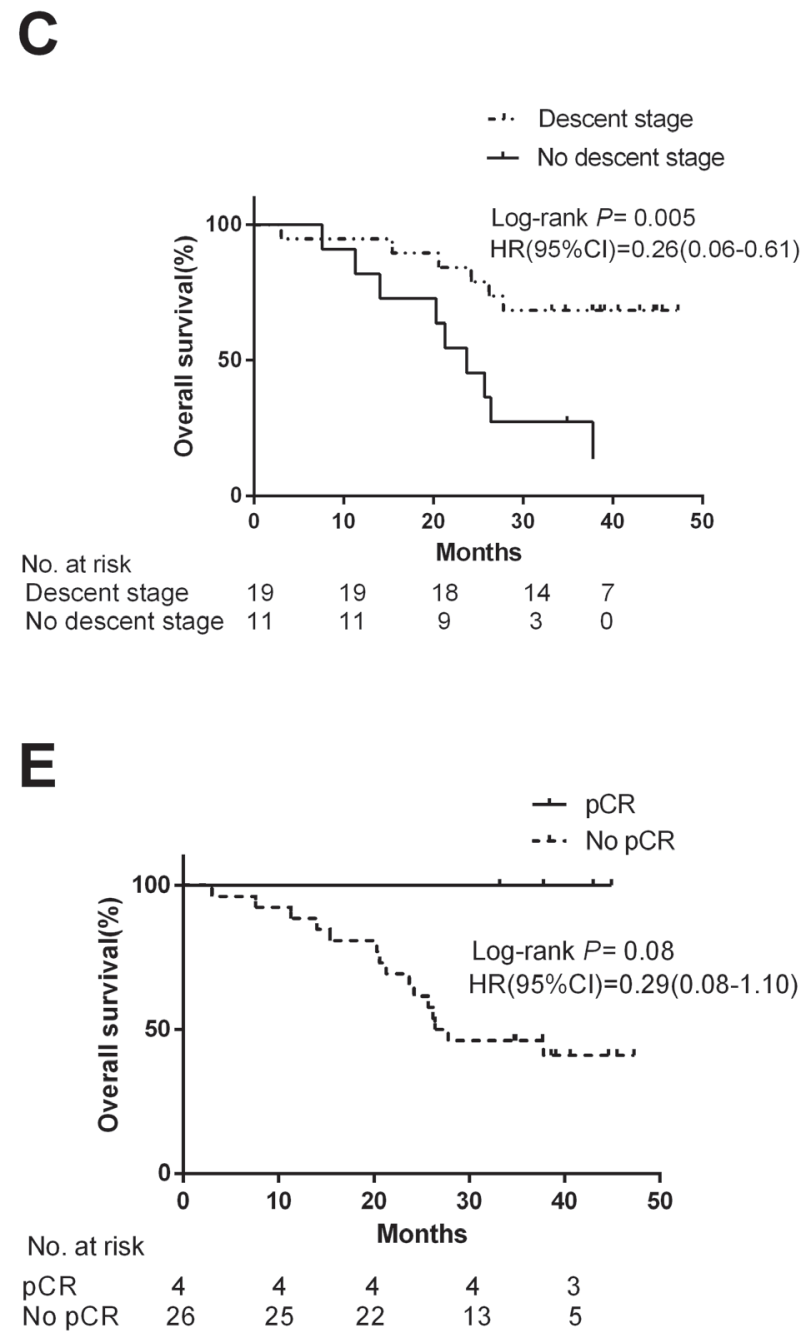

B

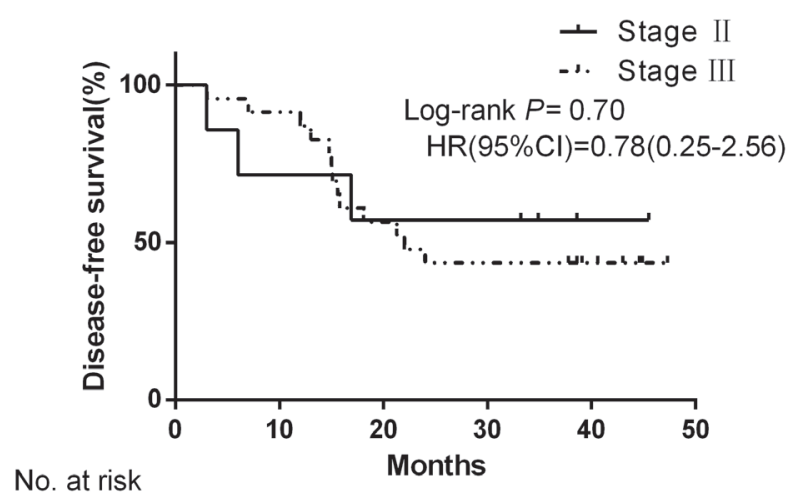

D

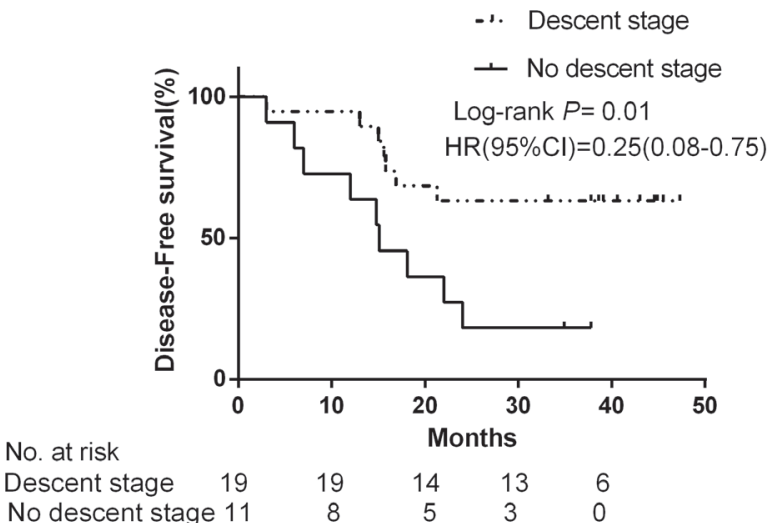

$\mathbf{F}$

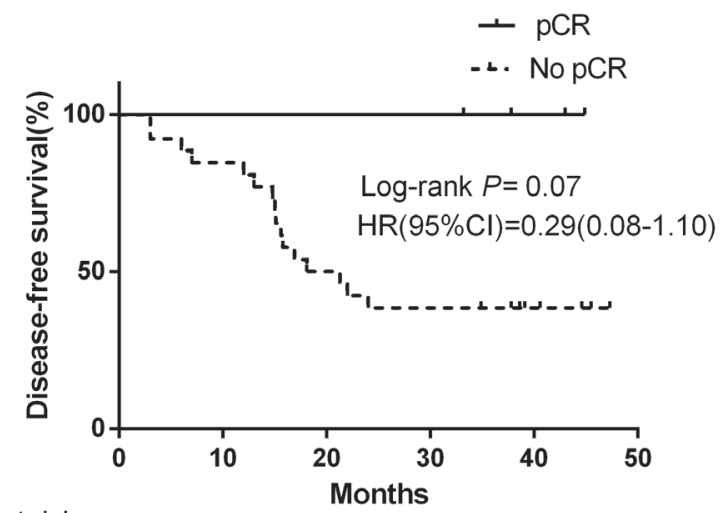

No. at risk

$\begin{array}{lrcccc}\text { pCR } & 4 & 4 & 4 & 4 & 3 \\ \text { No pCR } & 26 & 25 & 22 & 13 & 5\end{array}$

Figure 3: Kaplan-Meier analysis of progression-free survival (PFS) and overall survival (OS) of patients in different groups. Figure 3 A.-B. OS and DFS were not significantly different between patients with stage II and stage III disease. Figure 3 C.-D. Median OS and DFS of descent stage patients were significantly longer than of no descent stage patients. Figure 3 E.-F. Median OS and DFS were longer in $\mathrm{pCR}$ patients than in non-pCR patients but that difference did not reach significance. 
stage III disease (Figure 3A-3B). Median OS and DFS of down-staged (descent stage) patients were significantly longer than of non-downstaged (no descent stage) patients (HR: $0.26,95 \%$ CI: 0.06- $0.61 ; P=0.005$ and HR: 0.25 , 95\% CI: $0.08-0.75 ; P=0.01$, respectively) (Figure 3C3D). Median OS and DFS were longer in $\mathrm{pCR}$ patients than in non-pCR patients but that difference did not reach significance $(P=0.08$ and $P=0.07$, respectively) (Figure 3E-3F).

\section{Adverse events}

All patients were assessable for treatment-related toxicities. Adverse events (AEs) are summarized in Table 3. The G3 toxicities occurring in the course of neoadjuvant chemotherapy included neutropenia $(3 / 35,8.6 \%)$, anemia $(3 / 35,8.6 \%)$, thrombocytopenia $(2 / 35,5.7 \%)$, febrile neutropenia $(3 / 35,8.6 \%)$, nausea $(2 / 35,5.7 \%)$, as well as vomiting $(4 / 35,11.4 \%)$. The G4 toxicities only consisted of neutropenia $(1 / 35,2.9 \%)$ and vomiting $(1 / 35,2.9 \%)$ (Table 3$)$. No treatment-related mortality was observed before or after surgery. No dosage reductions were necessary during the neoadjuvant period. Complications associated with surgery included one case of anastomotic leak $(1 / 30,3.3 \%)$. During the adjuvant chemotherapy period, G3 and G4 hematologic AEs were observed in 5 $(5 / 24,20.8 \%)$ patients, in whom the dose of nab-PC was reduced by $20 \%$.

\section{PATIENTS AND METHODS}

\section{Eligibility}

Treated patients met the following inclusion criteria: (I) age ranges from 18 to 70 years, (II) ECOG Performance Status 0-1, (III) biopsy-proven resectable locally advanced thoracic ESCC, (IV) untreated clinical stage IIA to IIIC as assessed by enhancement computed tomography (CT) scan and/or positron tomography (PET/ CT) scan, and endoscopic ultrasound (EUS), (V) tumor location with middle third and distal third of esophagus, (VI) adequate bone marrow, hepatic and renal function, (VII) non-pregnant and non-breast feeding, (VIII) no prior invasive malignancy, (IX) not any prior anticancer therapy, and, (X) tumor can be measured according to RECIST criteria. All patients provided written informed consent. Ethical committee approval was given, and the trial was registered on the ClinicalTrials.gov Web site (NCT01258192). Exclusion reasons comprise: (I) carcinoma at the upper part of esophagus, (II) histologic diagnosis of adenocarcinoma of esophagus, (III) prior treatment for esophageal cancer, (IV) active infection, (V) pregnant or breast feeding, (VI) history of significant neurological or mental disorder, including seizures or dementia, and, (VII) prior invasive malignancy in previous 5 years (except for carcinoma in situ).

\section{Pretreatment tests and staging}

Pretreatment clinical tests include history, clinical examination, routine laboratory blood tests, endoscopy with biopsy, bronchoscopy, respiratory function tests, and ECG. Staging was performed by enhancement thoracoabdominal CT scan and/or PET/CT scan and EUS based on the 7th Union for International Cancer Control TNM classification [19]. Cervical ultrasound and radionucleotide bone scan were optional.

\section{Treatments}

Enrollment was performed by the clinicians and all eligible patients received nab-PC $\left(100 \mathrm{mg} / \mathrm{m}^{2}, \mathrm{~d} 1\right.$, $\mathrm{d} 8, \mathrm{~d} 22$ and $\mathrm{d} 29)$ and cisplatin $\left(75 \mathrm{mg} / \mathrm{m}^{2}, \mathrm{~d} 1\right.$ and $\left.\mathrm{d} 22\right)$ as neoadjuvant chemotherapy (Figure 1), followed by esophagectomy and adjuvant chemotherapy with or without radiotherapy.

Neoadjuvant chemotherapy: Neoadjuvant chemotherapy was composed of two cycles of nabPC and cisplatin. All chemotherapy agents were dosed based on actual body surface area. Nab-PC $100 \mathrm{mg} / \mathrm{m}^{2}$ was delivered by intravenous infusion on day 1, 8, 22 and 29. Cisplatin $75 \mathrm{mg} / \mathrm{m}^{2}$ was delivered by intravenous infusion on day 1 and 22. Prophylactic use of granulocyte colony stimulating factor (G-CSF) before neoadjuvant chemotherapy was not allowed.

Surgery: All enrolled patients underwent clinical reevaluation 3 weeks (day43) after termination of the second cycle of neoadjuvant chemotherapy, including physical examination, weight evaluation, blood laboratory analysis, and thoracoabdominal enhancement $\mathrm{CT}$ scan. If there was no evidence of metastatic disease, curative resection was carried out. Surgery was performed approximately 4 to 8 weeks after completion of neoadjuvant chemotherapy. The surgical procedure was selected by the surgeon according to tumor site, tumor stage and local practice. Esophagectomy approaches were transthoracic, transhiatal, or thoracoabdominal. Esophagectomy methods applied in this study include Ivor-Lewis and McKeown. Overlying pleura and adjacent soft tissues were included to ensure adequate radial margins. Nodal staging was recommended.

Postoperation treatment: Two cycles of adjuvant chemotherapy with the same regimen (nab-PC and cisplatin) were given starting 4-6 weeks after the resection. Postoperative three-dimensional conformal radiotherapy was permitted and was selected by the radiation therapist according to tumor stage. Radiotherapy was given after 2 cycles of adjuvant chemotherapy. The dose and fractionation regimen was either 50.4 Gy in 28 fractions 
or abiologically equivalent dose.

\section{Dose modifications}

If disease progression or new metastasis occurred in the course of neoadjuvant chemotherapy, the second cycle was not permitted and immediate surgery was mandated. Dose modification was carried out for agents based on their estimated causal relationship to the toxicity. Doses of nab-PC and cisplatin were reduced by $20 \%$ in the second cycle if grade 4 neutropenia, anemia, or thrombocytopenia was observed. The dose of cisplatin was reduced by $20 \%$ in the second cycle if creatinine clearance $(\mathrm{CCr})$ was $50 \leq$ $\mathrm{CCr}<60$, by $40 \%$ if $\mathrm{CCr}$ was $40 \leq \mathrm{CCr}<50$, and stopped if $\mathrm{CCr}$ was $<40 \mathrm{~mL} / \mathrm{min}$, or ototoxicity of grade 2 or higher was observed.

\section{Pathologic analysis}

The histopathological investigations included hematoxylin and eosin (HE) staining and were performed by two professional pathologists independently of each other. Histopathologic examination indicated whether the resection was defined as curative (R0) or whether there was residual microscopic disease (R1) or macroscopic tumor (R2). Pathologic response to the neoadjuvant chemotherapy was defined by tumor regression grade according to the Mandard classification [20].

\section{Study endpoints}

The primary study endpoint was pCR. The secondary endpoints included R0 resection rate, downstaging rate, effectiveness, safety, 3-year overall survival (3-y OS) and 3-year disease-free survival (3-y DFS). pCR was defined as no viable residual tumor cells. Near pCR was defined as $\leq 10 \%$ residual carcinoma in patients who did not qualify as pCR [21]. OS was recorded from the initiation of recruitment to the date of death or that of the last follow-up visit. DFS were calculated from the date of recruitment to documented progression or the date of death. Tumor response was evaluated for patients who had measurable lesions according to RECIST version 1.1.

\section{Follow-up}

Patients were followed-up every 3 months during the first 2 years after date of recruitment, and every 6 months from the third year onwards. Disease recurrence was defined as locoregional (esophageal bed or anastomotic or regional lymph nodes) or metastatic (supraclavicular lymphnodes or distant organs). A clinical examination and thoracoabdominal enhancement CT were performed every time. Follow-up was complete for all the 30 patients who underwent surgery, with a median 37.8 months of followup.

\section{Statistical analysis}

The sample size was determined by the Simon twostage design method. The study was continued when there were at least $20 \%(2 / 10)$ pCR at stage 1 . Then the study proceeded to the second stage with a total sample size of 30 patients. Our report reflects the final analysis after long-term follow-up. The Kaplan-Meier method was used. Corresponding HRs were calculated with 95\% CIs using the Cox proportional hazards model. The Cox proportional model was used to evaluate various prognostic factors. Analyses were conducted using the computer software SPSS version 17.0 (SPSS Inc., Chicago, IL, USA).

\section{Adverse events}

AEs were graded using CTCAE Version 4.0. AEs were recorded from the day of enrollment to 30 days following the accomplishment of treatments and were summarized as frequency and percent. When a patient suffered a particular AE event several times, only the highest grade was considered. A stopping rule was included for $\mathrm{AE}$ in this trial. If 2 of the first 10 patients or if $30 \%$ or more patients suffered grade $\geq 4$ non-hematologic AEs that were possibly related to treatment, the team was required to review the data before proceeding patient recruitment further.

\section{DISCUSSION}

Our trial explored the benefits and safety of weekly nab-PC and cisplatin chemotherapy as a neoadjuvant strategy for locally advanced resectable ESCC, including $77.1 \%(27 / 35)$ stage III patients. The approach not only resulted in a $100 \% \mathrm{R} 0$ resection rate, and a $63.3 \%(19 / 30)$ down-staging rate, but also came at a satisfactory OS and DFS rate with tolerable toxicity. The response rate observed in our study was encouraging, with a pCR plus near pCR rate of $20 \%$ (13.3\% plus $6.7 \%)$. That $13.3 \%$ (4/30) pCR rate exceeds the $0 \%-7.7 \%$ pCR rates reported for other cisplatin-based regimens [22-24].

Firstly, the most important result from our study was that a $63.3 \%$ down-staging rate was achieved with neoadjuvant combination treatment with weekly nabPC and cisplatin, and down-staged patients showed significantly longer survival than patients without downstaging. The correlation between down-staging and histological response to any preoperative therapy and prognosis has been reported previously in $\operatorname{ESCC}[7,25]$. This finding was in according with other studies indicating that down-staging with preoperative therapy could result in achieving a high tumor response and improving the 
complete resection rate and prolonging survival. That $63.3 \%$ down-staging rate exceeds the down-staging rates reported for other cisplatin-based regimens. Thus, this encouraging result indicates that evaluation of nab-PC and cisplatin as neoadjuvant chemotherapy regimens in randomized trials seems to be warranted.

There was also a significant relationship between pCR and DFS/OS. Our findings are in line with other studies demonstrating that achievement of a pCR is associated with better DFS and OS [26-28]. For instance, the RTOG trial 8911 showed that patients who achieved a pCR following preoperative therapy had a significantly improved DFS when compared with non-pCR patients [25]. Both RTOG 8911 and OEO2, another large trial of preoperative chemotherapy in resectable esophageal cancer, have also shown that unless patients did undergo R0 resection their overall survival remained very poor [25-28]. These results also imply that a major effect of neoadjuvant chemotherapy is to reduce tumor volume thereby increasing the potential for $\mathrm{R} 0$ resection.

With a median follow-up of 37.8 months, in our study 16/30 (50.4\%) patients were still alive and 14/16 $(87.5 \%)$ patients were alive without disease relapse. One-, 2- and 3-year OS rates were 90.0\%, 70.0\% and $43.3 \%$ respectively. By contrast, the INT0113 study, which comprised $49 \%$ patients with ESCC, showed no difference in OS between the neoadjuvant chemotherapy group and the surgery alone group [12]. First results from the British MRC study (33\% ESCC) published in 2002 showed that neoadjuvant chemotherapy with cisplatin and 5-FU increased the 2-year survival rate from $34 \%$ to $43 \%$, and the R0 resection rate from $54 \%$ to $60 \%$ [28]. The updated survival data from that study further suggested that the 5-year survival rate was $23 \%$ in the neoadjuvant chemotherapy group, being significantly higher than $17.1 \%$ in the surgery group [13]. In our study the R0 resection rate reached $100 \%$ and the 2-year OS rate increased to $69.8 \%$, both being obviously better than in INT0113 and the MRC study $[12,13]$. It therefore seems that weekly nab-PC and cisplatin as a neoadjuvant chemotherapy for locally advanced ESCC might be a promising alternative. Moreover, when compared with results from a phase II study of concurrent chemoradiotherapy for inoperable ESCC [29], our 1-year (90\% vs 75\%), 2-year (70\% vs 54\%) and 3-year survival rates $(43.3 \%$ vs $41 \%)$ seem encouraging.

In order to demonstrate the value of neoadjuvant chemotherapy for locally advanced ESCC, several trials were also run one after another in Japan [30-32]. The JCOG9907 study on resectable stage II/III ESCC demonstrated that the 5-year OS was significantly improved by neoadjuvant chemotherapy consisting of two courses of cisplatin plus 5-fluorouracil compared with postoperative chemotherapy $(55 \%$ vs $43 \%, P=0.04)$. Consequently, the standard of care for locally advanced thoracic esophageal cancer in Japan has changed from postoperative to preoperative chemotherapy [32]. When focusing on patients with stage III disease, which constitute a higher percentage in our study than in the JCOG9907 study (77.1\% vs51\%), our 3-year OS rate was $50.4 \%$ and the 5-year OS has not been reached yet.

Besides provisional evidence of superior efficacy, the toxicity profile of weekly nab-PC plus cisplatin was also favorable. In the study, $100 \%$ patients completed 2 cycles of neoadjuvant chemotherapy without dosage reduction. Compared to a phase II study of concurrent chemoradiotherapy using sb-PC plus cisplatin for inoperable ESCC [29], grade 3 and 4 neutropenia was lower $(11.5 \%$ vs $61.9 \%)$. During the adjuvant chemotherapy period, grade 3 and 4 hematologic AEs were observed only in $5(20.8 \%)$ patients. Triple-modality therapy, including radiotherapy, chemotherapy and surgery, is widely considered to be a standard treatment for locally advanced esophageal cancer [29, 33-40]. It seems, however, that concurrent chemoradiation can be accompanied with more severe toxicities and a greater risk of operative mortality [10, 41-44]. For instance, in the CROSS study (including 23\% squamous cell carcinoma) [33], anastomotic leak occurred in 36 (22\%) patients and $10(6 \%)$ deaths came up after surgery in the chemoradiotherapy and surgery group. In the Stahl study, operative mortality is raised to $10.2 \%$ after chemoradiotherapy vs 3.8\% in surgery alone group [45]. In our study, no treatment-related mortality was observed before or after surgery, and complications associated with surgery consisted of only one case of anastomotic leak (3.3\%). Some mature data, take JCOG9907 and OEO2 trials for example, confirm survival advantages for patients with locally advanced resectable esophageal cancer treated by preoperative chemotherapy with a non-elevated risk of complications or postoperative mortality [13, 28,46-48], which is consistent with our results. Thus, our data show that the two-drug-based regimen of nab-PC and cisplatin as a neoadjuvant chemotherapy is safe and feasible in locally advanced ESCC.

To the best of our knowledge, this clinical trial seems to be the first one evaluating the efficiency and safety of the combination of nab-PC and cisplatin as preoperative chemotherapy for the treatment of resectable ESCC. However, we have to admit that when compared with other similar clinical researches, the biggest weakness in this study is that the sample size is rather small. Moreover, with a short median follow-up period, the study so far provides no sound overall survival data at 5 years.

In conclusion, our data demonstrate that a combination regimen of nab-PC and cisplatin as neoadjuvant chemotherapy shows high activity in terms of $100 \%$ R0 resection, $63.3 \%$ down-staging rate and $13.3 \%$ pCR rate, and is safe in patients with locally advanced ESCC. Moreover, our data also indicate that the achievement of a pCR to neoadjuvant weekly nab- 
paclitaxel plus cisplatin chemotherapy might serve as a predictor of favorable outcome. Thus, evaluation of nab-PC and cisplatin in randomized trials seems to be warranted.

\section{ACKNOWLEDGMENTS}

We would like to thank all the patients and their families who participated in this study.

financial Support: This work was supported by Natural Science Foundation of China (81402429, 81372263), and Natural Science Foundation of Zhejiang Province, China (LQ14H160003). The funders had no role in study design, data collection, decision to publish, or preparation of the manuscript.

\section{CONFLICTS OF INTEREST}

The author has declared no conflicts of interest.

\section{REFERENCES}

1. Pohl H, Sirovich B, Welch HG. Esophageal adenocarcinoma incidence: are we reaching the peak? Cancer Epidemiol Biomarkers Prev. 2010; 19:1468-1470.

2. Zheng R, Zeng H, Zhang S, Chen T, Chen W. National estimates of cancer prevalence in China, 2011. Cancer Lett. 2016;370:33-38.

3. Purwar P, Bambarkar S, Jiwnani S, Karimundackal G, Laskar SG, Pramesh CS. Multimodality management of esophageal cancer. Indian J Surg. 2014;76:494-503.

4. Almhanna K, Shridhar R, Meredith KL. Neoadjuvant or adjuvant therapy for resectable esophageal cancer: Is there a standard of care? Cancer Control. 2013;20: 89-96.

5. Law S, Fok M, Chow S, Chu KM, Wong J. Preoperative chemotherapy versus surgical therapy alone for squamous cell carcinoma of the esophagus: a prospective randomized trial. J Thorac Cardio vasc Surg. 1997;114:210-217.

6. Maipang $\mathrm{T}$, Vasinanukorn $\mathrm{P}, \quad$ Petpichetchian C, Chamroonkul S, Geater A, Chansawwaang S, Kuapanich R, Panjapiyakul C, Watanaarepornchai $\mathrm{S}$, Punperk S. Induction chemotherapy in the treatment of patients with carcinoma of the esophagus. . J Surg Oncol.1994;56:191-197.

7. Ancona E, Ruol A, Santi S, Merigliano S, Sileni VC, Koussis H, Zaninotto G, Bonavina L, Peracchia A. Only pathologic complete response to neoadjuvant chemotherapy improves significantly the long term survival of patients with resectable esophageal squamous cell carcinoma: final report of a randomized, controlled trial of preoperative chemotherapy versus surgery alone. Cancer. 2001;91:2165-2174
8. Wang F, Wang YM, He W, Li XK, Peng FH, Yang XL, Fan QX. Chemoradiotherapy followed by surgery could improve the efficacy of treatments in patients with resectable esophageal carcinoma. Chin Med J (Engl). 2013; 126:3138-3145.

9. Lutz MP, Zalcberg JR, Ducreux M, Ajani JA, Allum W, Aust D, Bang YJ, Cascinu S, Hölscher A, Jankowski J, Jansen EP, Kisslich R, Lordick F et al. Highlights of the EORTC St. Gallen International Expert Consensus on the primary therapy of gastric, gastroesophageal and oesophageal cancer-differential treatment strategies for subtypes of early gastroesophageal cancer. Eur J Cancer. 2012;48:2941-2953.

10. Mariette C, Dahan L, Mornex F, Maillard E, Thomas PA, Meunier B, Boige V, Pezet D, Robb WB, Le Brun-Ly V, Bosset JF, Mabrut JY, Triboulet JP et al. Surgery alone versus chemoradiotherapy followed by surgery for stage I and II esophageal cancer: Final analysis of randomized controlled phase III trial FFCD 9901. J Clin Oncol. 2014;32:2416-2422.

11. Sjoquist KM, Burmeister BH, Smithers BM, Zalcberg JR, Simes RJ, Barbour A, Gebski V; Australasian GastroIntestinal Trials Group. Survival after neoadjuvant chemotherapy or chemoradiotherapy for resectable oesophageal carcinoma: an updated meta-analysis. Lancet Oncol. 2011;12:681-692.

12. Kelsen DP, Ginsberg R, Pajak TF, Sheahan DG, Gunderson L, Mortimer J, Estes N, Haller DG, Ajani J, Kocha W, Minsky BD, Roth JA. Chemotherapy followed by surgery compared with surgery alone for localized oesophageal cancer. N Engl J Med. 1998;339:1979-1984.

13. Allum WH, Stenning SP, Bancewicz J, Clark PI, Langley RE. Long-term results of a randomized trial of surgery with or without preoperative chemotherapy in esophageal cancer. J Clin Oncol. 2009;27:5062-5067.

14. Taxol ${ }$ (paclitaxel) injection [package insert]. Princeton, NJ: Bristol-Myers Squibb; 2011.

15. Abraxane ${ }^{\circledR}$ for injectable suspension (paclitaxel proteinbound particles for injectable suspension) (albumin-bound). Summit, NJ: Celgene Corporation; 2014.

16. Desai N, Trieu V, Yao Z, Louie L, Ci S, Yang A, Tao C, De T, Beals B, Dykes D, Noker P, Yao R, Labao E, et al. Increased antitumor activity, intratumor paclitaxel concentrations, and endothelial cell transport of cremophorfree, albumin-bound paclitaxel, ABI-007, compared with cremophor-based paclitaxel. Clin Cancer Res. 2006;12(4):1317-1324.

17. Socinski MA, Bondarenko I, Karaseva NA, Makhson AM, Vynnychenko I, Okamoto I, Hon JK, Hirsh V, Bhar P, Zhang H, Iglesias JL, Renschler MF. Weekly nabpaclitaxel in combination with carboplatin versus solventbased paclitaxel plus carboplatin as first-line therapy in patients with advanced non-small cell lung cancer: final results of a phase III trial. 2012;30:2055-2062. 
18. Shi Y, Qin R, Wang ZK, Dai GH. Nanoparticle albuminbound paclitaxel combined with cisplatin as the firstline treatment for metastatic esophageal squamous cell carcinoma. Onco Targets Ther. 2013; 6:585-591.

19. Sobin LH, Gospodarowicz MK, Wittekind C. TNM classification of malignant tumors. 7th ed. Oxford: WileyBlackwell; 2010.

20. Mandard AM, Dalibard F, Mandard JC, Marnay J, HenryAmar M, Petiot JF, Roussel A, Jacob JH, Segol P, Samama G, et al. Pathologic assessment of tumor regression after preoperative chemoradiotherapy of esophageal carcinoma: Clinicopathologic correlations. Cancer. 1994;73:2680-2686.

21. Wu TT, Chirieac LR, Abraham SC, Krasinskas AM, Wang H, Rashid A, Correa AM, Hofstetter WL, Ajani JA, Swisher SG. Excellent interobserver agreement on grading the extent of residual carcinoma after preoperative chemoradiation in esophageal and esophagogastric junction carcinoma: a reliable predictor for patient outcome. Am J Surg Pathol. 2007;31:58-64.

22. Cunningham D, Allum WH, Stenning SP, Thompson JN, Van de Velde CJ, Nicolson M, Scarffe JH, Lofts FJ, Falk SJ, Iveson TJ, Smith DB, Langley RE, Verma $\mathrm{M}$ et al. Perioperative chemotherapy versus surgery alone for resectable gastroesophageal cancer. N Engl J Med. 2006;355: 11-20.

23. Ychou M, Boige V, Pignon JP, Conroy T, Bouché O, Lebreton G, Ducourtieux M, Bedenne L, Fabre JM, Saint-Aubert B, Genève J, Lasser $\mathrm{P}$, Rougier $\mathrm{P}$. Perioperative chemotherapy compared with surgery alone for resectable gastroesophageal adenocarcinoma: an FNCLCC and FFCD multicenter phase III trial. J Clin Oncol. 2011;29: 1715-1721.

24. Schuhmacher C, Gretschel S, Lordick F, Reichardt P, Hohenberger W, Eisenberger CF, Haag C, Mauer ME, Hasan B, Welch J, Ott K, Hoelscher A, Schneider PM et al. Neoadjuvant chemotherapy compared with surgery alone for locally advanced cancer of the stomach and cardia: European Organisation for Research and Treatment of Cancer randomized trial 40954. J Clin Oncol. 2010;28: 5210-5218.

25. Kelsen DP, Winter KA, Gunderson LL, Mortimer J, Estes NC, Haller DG, Ajani JA, Kocha W, Minsky BD, Roth JA, Willett CG; Radiation Therapy Oncology Group; USA Intergroup. Long-term results of RTOG trial 8911 (USA Intergroup 113): A random assignment trial comparison of chemotherapy followed by surgery compared with surgery alone for oesophageal cancer. J Clin Oncol. 2007;25:3719-3725.

26. Pasini F, de Manzoni G, Zanoni A, Grandinetti A, Capirci C, Pavarana M, Tomezzoli A, Rubello D, Cordiano C. Neoadjuvant therapy with weekly docetaxel and cisplatin, 5-fluorouracil continuous infusion, and concurrent radiotherapy in patients with locally advanced esophageal cancer produced a high percentage of long-lasting pathological complete response: a phase 2 study. Cancer.
2013;119: 939-945

27. Lorenzen S, Thuss-Patience P, Al-Batran SE, Lordick F, Haller B, Schuster T, Pauligk C, Luley K, Bichev D, Schumacher G, Homann N. Impact of pathologic complete response on disease-free survival in patients with esophagogastric adenocarcinoma receiving preoperative docetaxel-based chemotherapy. Ann Oncol. 2013; 24: 20682073.

28. Medical Research Council Oesophageal Cancer Working Party: Surgical resection with or without preoperative chemotherapy in oesophageal cancer: A randomised controlled trial. Lancet. 2002 ;359:1727-1733.

29. Tang HR, Ma HF, An SM, Badakhshi H, Deng JY, Zhang JH, Chen Y, Zhang Z, Guo XM, Jiang GL, Zhao KL. A phase II study of concurrent chemoradiotherapy with paclitaxel and cisplatin for inoperable esophageal squamous cell carcinoma. Am J Clin Oncol. 2014. [Epub ahead of print]

30. Hara H, Tahara M, Daiko H, Kato K, Igaki H, Kadowaki S, Tanaka Y, Hamamoto Y, Matsushita H, Nagase M, Hosoya Y. Phase II feasibility study of preoperative chemotherapy with docetaxel, cisplatin, and fluorouracil for esophageal squamous cell carcinoma. Cancer Sci. 2013;104:1455-1460.

31. Nakamura K, Kato K, Igaki H, Ito Y, Mizusawa J, Ando N, Udagawa H, Tsubosa Y, Daiko H, Hironaka S, Fukuda H, Kitagawa Y; Japan Esophageal Oncology Group/ Japan Clinical Oncology Group. Three-arm phase III trial comparing cisplatin plus 5-FU (CF) versus docetaxel, cisplatin plus 5-FU (DCF) versus radiotherapy with $\mathrm{CF}$ (CF-RT) as preoperative therapy for locally advanced esophageal cancer (JCOG1109, NExT study). Jpn J Clin Oncol. 2013;43:752-755.

32. Ando N, Kato H, Igaki H, Shinoda M, Ozawa S, Shimizu $H$, Nakamura $T$, Yabusaki $H$, Aoyama N, Kurita A, Ikeda K, Kanda T, Tsujinaka $\mathrm{T}$ et al. A randomized trial comparing postoperative adjuvant chemotherapy with cisplatin and 5-fluorouracil versus preoperative chemotherapy for localized advanced squamous cell carcinoma of the thoracic esophagus (JCOG9907). Ann Surg Oncol. 2012;19:68-74.

33. Hagen PV, Hulshof MC, van Lanschot JJ, Steyerberg EW, van Berge Henegouwen MI, Wijnhoven BP, Richel DJ, Nieuwenhuijzen GA, Hospers GA,Bonenkamp JJ, Cuesta MA, Blaisse RJ, Busch OR et al. Preoperative chemoradiotherapy for esophageal or junctional cancer. $\mathrm{N}$ Engl J Med. 2012;366:2074-2084.

34. Shapiro J, van Lanschot JJ, Hulshof MC, van Hagen P, van Berge Henegouwen MI, Wijnhoven BP, van Laarhoven HW, Nieuwenhuijzen GA, Hospers GA, Bonenkamp JJ, Cuesta MA, Blaisse RJ, Busch OR et al. CROSS study group. Neoadjuvant chemoradiotherapy plus surgery versus surgery alone for oesophageal or junctional cancer (CROSS): long-term results of a randomised controlled trial. Lancet Oncol. 2015; 16:1090-1098. 
35. Urba SG, Orringer MB, Turrisi A, Iannettoni M, Forastiere A, Strawderman M. Randomized trial of preoperative chemoradiation versus surgery alone in patients with locoregional esophageal carcinoma. J Clin Oncol. 2001;19:305-313.

36. Burmeister BH, Smithers BM, Gebski V, Fitzgerald L, Simes RJ, Devitt P, Ackland S, Gotley DC, Joseph D, Millar J, North J, Walpole ET, Denham JW et al. Surgery alone versus chemoradiotherapy followed by surgery for resectable cancer of the oesophagus: a randomised controlled phase III trial. Lancet Oncol. 2005;6:659-668.

37. Lee JL, Park SI, Kim SB, Jung HY, Lee GH, Kim JH, Song HY, Cho KJ, Kim WK, Lee JS, Kim SH, Min YI. A single institutional phase III trial of preoperative chemotherapy with hyperfractionation radiotherapy plus surgery versus surgery alone for resectable esophageal squamous cell carcinoma. Ann Oncol. 2004;15:947-954.

38. Tepper J, Krasna MJ, Niedzwiecki D, Hollis D, Reed CE, Goldberg R, Kiel K, Willett C, Sugarbaker D, Mayer R. Phase III trial of trimodality therapy with cisplatin, fluorouracil, radiotherapy, and surgery compared with surgery alone for esophageal cancer: CALGB 9781. J Clin Oncol. 2008;26:1086-1092.

39. McNamara MJ, Adelstein DJ, Bodmann JW, Greskovich JF Jr, Ives DI, Mason DP, Murthy SC, Rice TW, Saxton JP, Sohal D, Stephans K, Rodriguez CP, Videtic $\mathrm{GM}$ et al. A phase II trial of induction epirubicin, oxaliplatin, and fluorouracil, followed by surgery and postoperative concurrent cisplatin and fluorouracil chemoradiotherapy in patients with locoregionally advanced adenocarcinoma of the esophagus and gastroesophageal junction. J Thorac Oncol. 2014;9:1561-1567.

40. Ma HB, Di ZL, Wen J, Ke Y, Sun X, Ren J. Prospective, open, multicentre Phase I/II trial to assess safety and efficacy of neoadjuvant radiochemotherapy with docetaxel and cisplatin for esophageal carcinoma. Jpn J Clin Oncol. 2015;45:169-175.

41. Adelstein DJ, Rice TW, Rybicki LA, Larto MA, Ciezki J, Saxton J, DeCamp M, Vargo JJ, Dumot JA, Zuccaro G. Does paclitaxel improve the chemoradiotherapy of locoregionally advanced esophageal cancer? A nonrandomized comparison with fluorouracil-based therapy. J Clin Oncol. 2000;18:2032-2039.
42. Kelsey CR, Chino JP, Willett CG, Clough RW, Hurwitz HI, Morse MA, Bendell JC, D'Amico TA, Czito BG. Paclitaxel-based chemoradiotherapy in the treatment of patients with operable esophageal cancer. Int J Radiat Oncol Biol Phys. 2007;69:770-776.

43. Juloori A, Tucker SL, Komaki R, Liao Z, Correa AM, Swisher SG, Hofstetter WL, Lin SH. Influence of preoperative radiation field on postoperative leak rates in esophageal cancer patients after trimodality therapy. J Thorac Oncol. 2014;9:534-540.

44. Lockhart AC, Reed CE, Decker PA, Meyers BF, Ferguson MK, Oeltjen AR, Putnam JB, Cassivi SD, Montero AJ, Schefter TE; American College of Surgeons Oncology Group. Phase II study of neoadjuvant therapy with docetaxel, cisplatin, panitumumab and radiation therapy followed by surgery in patients with locally advanced adenocarcinoma of distal esophagus (ACOSOG Z4051). Ann Oncol. 2014;25:1039-1044.

45. Stahl M, Walz MK, Stuschke M, Lehmann N, Meyer HJ, Riera-Knorrenschild J, Langer P, Engenhart-Cabillic R, Bitzer M, Königsrainer A, Budach W, Wilke H. Phase III comparison of preoperative chemotherapy compared with chemoradiotherapy in patients with locally advanced adenocarcinoma of the esophagogastric junction. J Clin Oncol. 2009: 27: 851-856.

46. Gebski V, Burmeister B, Smithers BM, Foo K, Zalcberg J, Simes J; Australasian Gastro-Intestinal Trials Group. Survival benefits from neoadjuvant chemoradiotherapy or chemotherapy in oesophageal carcinoma: A meta-analysis. Lancet Oncol. 2007;8:226-234.

47. Thirion P, Michiels S, Le Maitre A. Individual patient databased meta-analysis assessing the interest of pre-operative chemotherapy in resectable oesophageal carcinoma. J Clin Oncol. 2007;25:200s, (suppl; abstr 4512)

48. Hirao M, Ando N, Tsujinaka $\mathrm{T}$, Udagawa $\mathrm{H}$, Yano M, Yamana H, Nagai K, Mizusawa J, Nakamura K; Japan Esophageal Oncology Group/Japan Clinical Oncology Group. Influence of preoperative chemotherapy for advanced thoracic oesophageal squamous cell carcinoma on perioperative complications. Br J Surg. 2011;98:1735-1741. 